\title{
Prevalence of Occupational Contact Dermatitis to Mercaptobenzothiazole in a Population of Seamen and Prognosis after 3-Year Evaluation
}

Loddé $\mathrm{B}^{1,2 *}$, Roguedas-Contios $\mathrm{AM}^{3}$, Pougnet $\mathrm{R}^{1,2}$, Paris $\mathrm{P}^{4}$, Jegaden $\mathrm{D}^{5}$, Misery $\mathrm{L}^{3}$ and Dewitte JD $\mathrm{D}^{1,2}$

${ }^{1}$ Université Européenne de Bretagne, France

${ }^{2}$ Université de Brest, France

${ }^{3}$ Service de dermatologie et vénéréologie, France

${ }^{4}$ Service de Santé des gens de mer Le Guilvinec, France

${ }^{5}$ Service de Santé au Travail en Iroise, France

\begin{abstract}
Background: The prevalence of contact dermatitis to mercaptobenzothiazole (MBT) in the maritime work place and its prognosis have been poorly studied.

Objectives: Determining the clinical presentation as well as the annual incidence rate of on set of skin allergies to MBT in the maritime workplace, and attempting to gauge the social and professional impact of this condition on affected seafarers.

Materials and methods: Analysis of the medical records of the seafarers who reported a skin allergy to MBT in 2008 , and calculation of the prevalence of this condition amongst the 35563 professional seafarers exposed to MBT in France because they wear work clothes made of synthetic rubber in their occupational activities (catch handling, merchant shipping or shellfish farming).

Results: We found only three cases in professional fishermen. In all cases, the dermatitis persisted despite the arrest of exposure to MBT, and made very difficult, the continuation of their professional life of these patients in the fishing sector.

Conclusion: The prevalence of contact dermatitis to MBT in the maritime sector is 1/10 000. The 3-year prognosis is poor since the seafarers affected by this disease reported the persistence of lesions and the healthimposed obligation to cease working in the fishing industry.
\end{abstract}

Keywords: MBT; Contact dermatitis; Occupational; Seafarer

\section{Introduction}

Though being well-known as allergens, mercaptobenzothiazole (MBT) and its derivatives are still widely used in natural and synthetic rubber $[1,2]$ used to make most of the personal protective equipment worn by vocational seafarers (Figure 1). However, the prevalence and the prognosis of contact dermatitis in seamen are not known. This study was aimed at gaining insight into the onset and development of contact dermatitis in MBT-sensitive individuals in the maritime activities and into its prevalence as well as its impact on the work.

\section{Materials and Methods}

Through the medical care provided by the French health office dedicated to seafarers we investigated the skin conditions associated with the wearing of protective gloves and how these problems could affect professional seafarers.

This exhaustive retrospective study was greatly facilitated by the requirement to be met by any active professional maritime staff member to visit, at least, once a year a doctor from the relevant health service within their maritime district. Moreover, in France, when a worker suffers from an occupational illness, a claim for compensation may be made with their social security and welfare office on condition that this illness is listed in a standard table of occupational diseases. Providing a medical certificate listing the presented lesions is a must to notify this affection.

For seafarers, 98 different tables are available: for each illness, not only are listed the symptoms and the paraclinical abnormalities corresponding to the reportable disease, but also the maximum timescale for their onset with respect to exposure to the triggering agent(s), and the type(s) of work liable to bring on the illness.

For eczema-type allergic lesions linked to sensitivity to a specific chemical or biological agent such as MBT, the relevant table is number $65[3]$.

In this study we, therefore, used the compensation claims falling under table 65 and made, in 2008, by professional seafarers to their social security and welfare institution. Then, we focused our investigations on the medical conditions that could be connected to an allergy to a specific piece of protective equipment. Finally, we questioned again the seafarers' health service doctor who had filled in the medical record.

In 2008, a total of 35563 people were registered in the maritime record. This population consisted of merchant seafarers, fishermen and shellfish farmers. All of the boots and most of the gloves used in their professional activities are made of synthetic rubber and contain MBT [4].

*Corresponding author: Brice Loddé, Université Européenne de Bretagne, France, Université de Brest, EA 4686 - CS 93837 - 29238 Brest Cedex 3; Service de Santé au Travail et Maladies liées à l'environnement, CHRU Morvan, 2 avenue FOCH, 29609 Brest Cedex, France, Tel: +0033298223509; Fax: +0033298223959; E-mail: Brice.lodde@chu-brest.fr

Received May 20, 2013; Accepted June 23, 2013; Published June 28, 2013

Citation: Loddé B, Roguedas-Contios AM, Pougnet R, Paris P, Jegaden D, et al (2013) Prevalence of Occupational Contact Dermatitis to Mercaptobenzothiazole in a Population of Seamen and Prognosis after 3-Year Evaluation. J Allergy Ther 4: 139. doi:10.4172/2155-6121.1000139

Copyright: ( 2013 Loddé B, et al. This is an open-access article distributed unde the terms of the Creative Commons Attribution License, which permits unrestricted use, distribution, and reproduction in any medium, provided the original author and source are credited. 
Citation: Loddé B, Roguedas-Contios AM, Pougnet R, Paris P, Jegaden D, et al. (2013) Prevalence of Occupational Contact Dermatitis to Mercaptobenzothiazole in a Population of Seamen and Prognosis after 3-Year Evaluation. J Allergy Ther 4: 139. doi:10.4172/21556121.1000139

Page 2 of 3

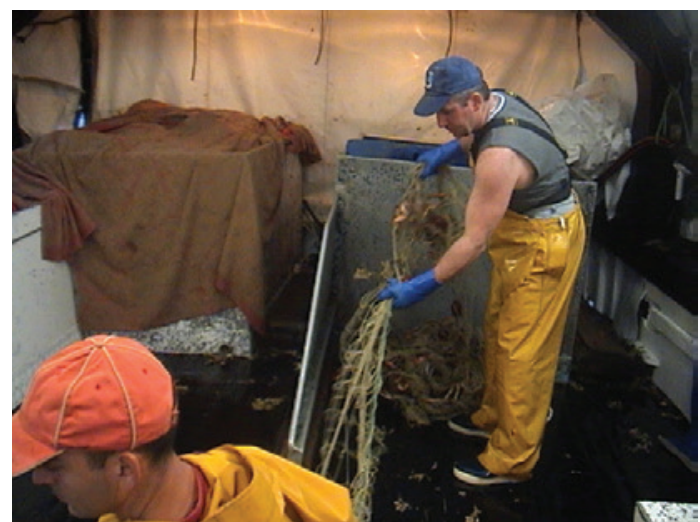

Figure 1: Professional fisherman wearing protective glove made with synthetic rubber.

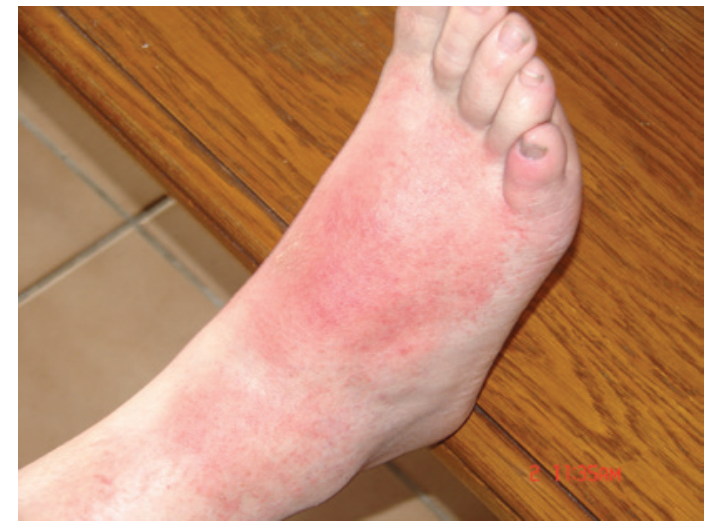

Figure 2: Foot attempt of the first observed fisherman.

All of these professionals must have an annual medical check-up by a seafarers' health service doctor to determine their medical fitness to continue carrying out professional activities in the maritime sector. We, thus, got informed on whether the declared illness had impacted on their ability to continue with professional activities.

Under the scope of this study, all of the seafarers' health service doctors were interviewed so as to find out if one or several of them had found out cases of contact dermatitis from exposure to MBT amongst the 35563 maritime staff under medical survey in 2008. The declared cases were then analyzed from a clinical point of view by considering the examination carried out and the relevance of the testing.

We also used the statistics of occupational illness recognition issued by the seafarers' health office to double check that they referred to the same cases as those found in the seafarers' health service files.

Finally, as part of the follow-up process, we interviewed the professional seafarers 3 years after the onset of their illness to get an overview of their current situation and to gain insight into their professional life over this 3-year period. Moreover, we examined them to find out if they still presented eczema scars, or scars from any other skin condition.

\section{Results}

Out of 35563 medical records of professional seafarers, we found only 3 cases of contact dermatitis from MBT in 2008. For the three of them claims for occupational illness under table 65 [5] were made.

The 3 cases under study are reported below:

The first case was that of a fisherman from the French west coast, who was 48 -year-old at diagnosis. He had been working as fisherman since the age of 18 . Contact dermatitis occurred on the legs and feet due to the boots he had to wear. No other part of his body was affected, and the eczema was eythemato-squamous (Figure 2). Pruritus was intense, and the patch tests were positive to MBT $(+++)$ and mercapto mix $(+++)$. After he had received a treatment, he wore MBT-free boots, but the dermatitis appeared again at work. He finally quitted his maritime job.

The second fisherman (from the French west coast too) was 43-yearold at diagnosis. He had also been a fisherman since the age of 18 . He presented with dishydrotic eczema on hands (Figure 3), arms, feet and legs when he was on board. Five years ago, he also developed the same form of dermatosis, and sensitivity to colophony was found. At the time of the second eruption, patch testing proved to be very positive to both MBT and mercapto mix (+++) (Figure 4). He changed his protective equipment but, after his sick leave, he had been able to board only for 6 months. Afterwards, he again presented with eruption on the same skin areas, which led to hospitalization. He also finally quitted his maritime occupation.

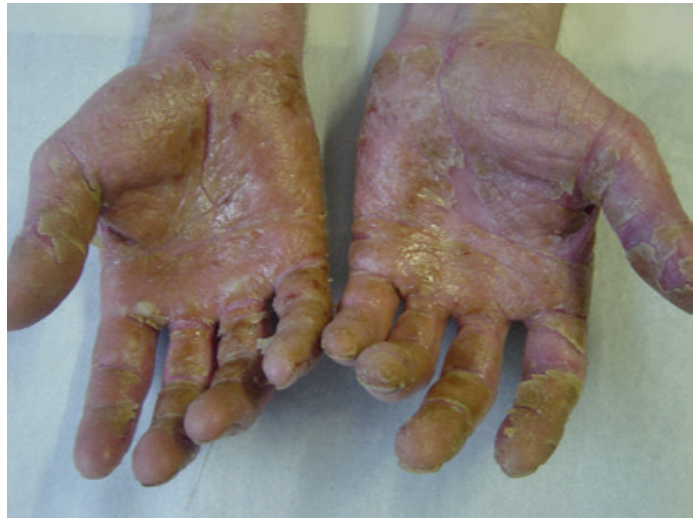

Figure 3: Hands attempt of the second observed fisherman.

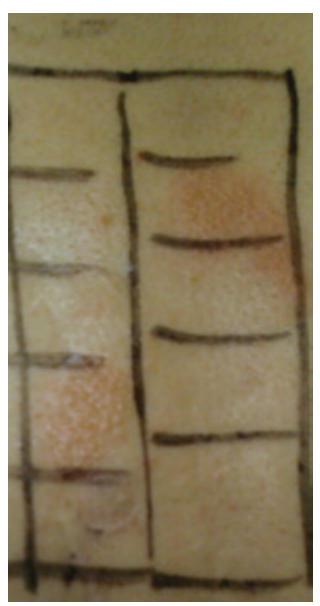

Figure 4: Positive patch testing to mercapto mix and mercaptobenzothiazole in second fisherman. 
Citation: Loddé B, Roguedas-Contios AM, Pougnet R, Paris P, Jegaden D, et al. (2013) Prevalence of Occupational Contact Dermatitis to Mercaptobenzothiazole in a Population of Seamen and Prognosis after 3-Year Evaluation. J Allergy Ther 4: 139. doi:10.4172/21556121.1000139

Page 3 of 3

The third fisherman, from the French south coast, was 42-year-old when he showed symptoms of dermatitis. He had worked on trawlers since the age of 16 . He has developed hyperkeratosic eczema on his palms and soles. Patch-tests were positive to latex and MBT (++). After many sick leaves, he had still skin eruptions even with MBT-free boots. The seafarer's health doctor finally declared him unfit for fishing. He changed to work on-board a ferry.

\section{Discussion}

Among a population of 35,563 people, we found only 3 cases of contact dermatitis to MBT. All cases were related to professional deepsea fishermen.

There is no doubt that exposure to MBT is higher in the fishing industry than in the merchant navy. Indeed, in most of on-board fishing activities gloves (fish sorting, fishing equipment handling, or others) seafarers wear rubber-made protection gloves. Furthermore, the gloves in use in shellfish farming are alike.

None of the 3 patients had history of any previous atopic or allergic diseases. All of them had been recognized by the seafarers' social institution as suffering from an occupational skin disease.

There are evidences of occupational contact dermatitis to MBT in the fishing industry. Nevertheless, they seem to have been neither widely described nor reported [6-10]. It is worth wondering why. First, fishermen are not ready for exploration of their occupational skin disease because they are afraid of losing their job in the event doctors would advise them to stop wearing MBT-containing pieces of protective equipment. In fact this allergy seems more to be hidden than searched in this population. Second, information about this skin condition may be missing among this population of workers. In other countries this contact dermatitis among this population does not seem to exist or is not diagnosed or other colleagues confronted with it had not reported it in the medical literature. Third, we are probably confronted with a healthy worker effect because the fishermen suffering from this kind of allergic diseases can decide to quit their occupation and, thus, be no longer subject to the systematic examinations for fitness by physicians.

Moreover, the process of sensitization seems to have a long life span (even more than 20 years). This could also explain the difficulty to diagnose this contact dermatitis in this population. Somehow, when dermatitis appears, the occlusion and humidity in boots or gloves can lead to persistence even though the subject wears MBT-free equipment [6]. Therefore, when a subject sensitive to MBT presents with eczema, in most cases, it results from an occupational sensitization [6]

Therefore, unfortunately, the hazards of this kind of disease are marked by the loss of the job in the fishing activity.

In a study by Geier et al. [11], 21\% of the patients with occupational contact dermatitis registered in the Information Network of Departments of Dermatology (IVDK) in the years 1995-2001 were patch-tested on suspicion of allergy to rubber gloves. Among the rubber allergens tested by these authors, the compounds of the Thiuram family were by far the most frequent ones in these patients. Sensitization to Mercapto mix appears in second place. According to the information provided to the authors by manufacturers, in recent years, dithiocarbamates and MBT derivatives were increasingly used in the protective glove-making industry. It is worth noting that, in this study, despite this increase, these allergens elicited positive reactions in only about $3 \%$ of the tested patients, and showed no increasing trend.

In the present study, none of the monitored seafarers showed sensitization to thiuram compounds.

In our study, out of the 35,563 people exposed to MBT, the 3 cases under study provide new epidemiological data about this working environment. Indeed, very few studies have led to the availability of prevalence figures in professional seafarers, although according to our study it accounts for about 1 case out of 10,000. It is definitely not a major health issue in the maritime sector, but it has to be known.

\section{Conclusion}

Occupational contact dermatitis to MBT does not seem to be very frequent in the fishing industry. It is caused by the wearing of the same wet and allergenic protective equipment, and a sensitivity process is developing after many working years. The prevalence found in this study was 1/10,000 in a population of professional fishermen in 2008 . The occupational prognosis of this disease is bad because it frequently compels the sensitized workers to quit their jobs.

\section{References}

1. Rose RF, Lyons $P$, Horne $H$, Mark Wilkinson S (2009) A review of the materials and allergens in protective gloves. Contact Dermatitis 61: 129-137.

2. Cleenwerk MB (2010) Gants de protection et santé au travail. Arch Mal Prof Env 71: 398-400

3. Loddé B, Jegaden D, Dewitte JD (2004) Maladies professionnelles cutanées maritimes. Nouv Dermatol 23: 458-464.

4. Adams AK, Yiannias JA (2008) Mercaptobenzothiazole and mercapto mix Dermatitis 19: E39-E41.

5. Le Bolloc'h M (2008) Rapport d'activité de l'Etablissement National des Invalides de la Marine pour l'année 2008. Consultable sur le site du ministère des transports français : 38 .

6. Adams AK, Warshaw EM (2006) Allergic contact dermatitis from mercapto compounds. Dermatitis 17: 56-70.

7. Cao LY, Taylor JS, Sood A, Murray D, Siegel PD (2010) Allergic contact dermatitis to synthetic rubber gloves: changing trends in patch test reactions to accelerators. Arch Dermatol 146: 1001-1007.

8. Le Coz CJ (2004) Allergy to mercaptobenzothiazole and mercapto mix. Ann Dermatol Venereol 131: 846-848

9. Nedorost S (2009) Clinical patterns of hand and foot dermatitis: emphasis on rubber and chromate allergens. Dermatol Clin 27: 281-287, vi.

10. Lucas R, Boniface K, Hite M (2010) Skin disorders at sea. Int Marit Health 61 : 9-12.

11. Geier J, Lessmann H, Uter W, Schnuch A; Information Network of Departments of Dermatology (IVDK) (2003) Occupational rubber glove allergy: results of the Information Network of Departments of Dermatology (IVDK), 1995-2001. Contact Dermatitis 48: 39-44 